\section{Nineteenth century kinetic theory}

\section{N. Feather}

The Kind of Motion We Call Heat: A History of the Kinetic Theory of Gases in the 19th Century. Book 1: Physics and the Atomists. Pp. xxxix + 1-302. Book 2: Statistical Physics and Irreversible Processes. Pp. xxxix + 303769. By S. G. Brush. (North-Holland: New York and Oxford, 1976.) Dfl. 210; $\$ 83.95$ the set.

IT is not until he reaches p168 of this weighty monograph that the author admits that its title is taken, in literal translation, from that of Clausius' paper of 1857 which, as he says, "defined the scope and viewpoint of most 19th-century work in the kinetic theory of gases". Nothing else in the monograph is similarly derivative. Since he was invited to deliver a seminar at Harvard in 1954, Dr Brush has immersed himself in his chosen subject, and has written copiously about it. The present publication is a re-presentation and up-dating of the contents of 17 articles (the author says 15) which appeared under his name (one with C. W. F. Everitt as collaborator) in various journals between 1957 and 1974. These have been organised in two sequences. In Book 1 are accounts of the relevant contributions of seven individuals, from John Herapath (1790 $1868)$ to Ernst Mach (1838-1916); in Book 2 discussions of seven 'problems' which exercised the minds of nineteenth century scientists and philosophers-problems ranging from "the wave theory of heat" to "Brownian movement". These two sequences are prefaced by a 100-page "introductory survey", specially written to give coherence to the whole work.

This is an interesting arrangement; however, as the author concedes, it "obviously entails considerable redundancy". "That may not be a disadvantage", he adds, optimistically, “... the reader can jump into the ... chapters in almost any order . . . without losing too much of the overall picture". Unhappily, such licence is not vouchsafed a revieweralthough when he meets an outline of the derivation of Boltzmann's $H$ theorem for the third time he is tempted to skip.

The chapters are divided into sections, and footnotes are collected together at the end of each section. There are some 108 sections so annotated, and with the number of sectional footnotes ranging from 1 to 59 , it will be clear that the publishers' claim that "the author's historical researches have gone far beyond any other books on the subject" has at least statistical justification. Moreover, the last 49 pages of the monograph contain a separate bibliography, with brief indication of content, of 539 publications, listed by authors arranged alphabetically. These publications, Dr Bush considers, constitute the essence of the matter, so far as the nineteenth century is concerned. $\mathrm{He}$ has cited "thousands" of others in the footnotes —but he admits that they are "minor works".

What, then, has this monumental effort achieved? A balanced account of the history of the development of the subject within the century surveyed - that cannot be gainsaid-and a redistribution of emphasis and credit. Credit to Herapath and Waterston for being in advance of their time (largely because the notion of heat as a wave process, which became popular in the early years of the ninteenth century, went far to diminishing the impact of the experimental researches of Rumford and Davy). Similar credit to Leslie as the first to distinguish the three modes of heat transfer. Credit to Loschmidt and E. P. Culverwell for pertinent criticisms which led Boltzmann to a deeper study of his statistical theory. And, in respect of the last years of the century, a reappraisal of the discontents which beset kinetic theorists generally-the problem of gaseous specific heats seen as a minor problem, in comparison with more fundamental doubts of a quasiphilosophical character concerning randomness and irreversibility.

No-one will read Dr Brush's account without having his horizons widened and his detailed knowledge of the history of the subject immeasurably increased. It must be said, however, that he is likely to be much irritated in the

\section{Sorry, for copyright reasons some images on this page may not be available online}

process. Leaving aside the 'redundancies' in text and footnotes (it would seem almost as if the field is wide enough to sustain an ergodic theorem in respect of the continuing theme of this book), he will be irritated by the numerous textual errors and misprints.

As a matter of interest, I checked the examples noticed during a single reading of chapters 11 and 12 against the relevant articles in American Journal of Physics whene the material was originally published. I found three cases in which a typographical or textual error was repeated from the original version, and fourteen examples of errors newly appearing-five in new matter, and nine in places where there had been no error before. One example of the latter class is particularly puzzling. On $\mathrm{p} 413$, the factor $(1+(b / \mathrm{v}))$ in equation (13)-which was correcthas been replaced by $(1-(b / v))^{-1}$, although the whole point of the argument in the following paragraph turns on the retention of the correct form in the equation.

There is an interestingly gratuitous error in the introductory survey (p43). Traversing a field of physics less familiar to him than gas theory, the author is presenting the old story of Fresnel and Poisson and diffraction by a circular disc. Poisson, he says, concluded that, if Fresnel were correct, "there should be ... a tiny bright spot at a certain distance behind the disk". When the test was made, "the bright spot appeared just where the mathematics predicted".

In a work of the magnitude before us, occasional errors are inevitable, but, sadly, there are more than they should be; and some will almost certainly mislead. American usage, too, is sometimes subtlely different from our own. One example will suffice. Cayley is described as a 'colleague' of Tait (p358). Cayley, however, had left Cambridge before Tait went up as an undergraduate; by the time he returned, Tait was already in Edinburgh. They were never workers in the same institution. This usage, however, seems not to be accidental. In his preface, Dr Brush has a list of 22 "colleagues", the world over, whom he thanks for "valuable suggestions and information". At least he does not call his helpers "co-efficients", as Kelvin did (preface, Baltimore Lectures). Incidentally, Kelvin's nephew, J. T. Bottomley, worked, not "in England" (p520), but in his uncle's laboratory in Glasgow-and Oliver Lodge published (in 1894), neither from London nor from Birmingham ( $\mathrm{p} 745$ ), but as professor in Liverpool. 